\title{
Parkinson's Disease: A Genetic Study
}

\author{
Ma. Elisa Alonso, Enrique Otero, Rosalinda D’Regules and Hector Hugo Figueroa
}

\begin{abstract}
A sample of 122 patients with Parkinson's Disease was studied for the purpose of investigating if the frequency of relatives affected with Parkinson in this group was higher than in a control group and to see if the genetic load was more important in some of the subtypes of Parkinson described by Barbeau and Pourcher (1982). ${ }^{7}$ In our 122 patients, we found that $1.7 \%$ were post-encephalic parkinsonian, $12.3 \%$ were symptomatic cases and $86 \%$ of the idiopathic variety. There were $16.1 \%$ early onset patients in the idiopathic group and among these we found $23.5 \%$ with a positive family history of Parkinson in the first-degree relatives. In 6 cases with the tremor onset form of the disease, the family history was positive and 5 patients, $4.7 \%$ had familial essential tremor-related Parkinsonism. Our results support Barbeau's hypothesis ${ }^{7.19}$ that Parkinson is a heterogeneous disease in which some subtypes (such as early onset Parkinson) have an important genetic subceptibility component.
\end{abstract}

RÉSUMÉ: Maladie de Parkinson: une étude génétique. Un échantillon de 122 patients souffrant de la maladie de Parkinson a été étudié dans le but d'examiner si la fréquence de la maladie de Parkinson est plus élevée dans leur parenté que dans un groupe témoin et pour voir si le fardeau génétique est plus important chez certains des sous-types de Parkinson décrits par Barbeau et Pourcher (1982) ${ }^{7}$ Parmi nos 122 patients, $1.7 \%$ présentaient un Parkinson post-encéphalitique, $12.3 \%$ présentaient un Parkinson secondaire et $86 \%$ un Parkinson idiopathique. Chez $16.1 \%$ du groupe idiopathique, le début de la maladie était précoce et parmi ceux-ci, $23.5 \%$ avaient une histoire familiale positive de maladie de Parkinson chez des membres de leur famille apparentés au premier degré. L'histoire familiale était positive chez 6 cas présentant la forme à début tremblant, alors que 5 patients, soit $4.7 \%$ des cas avaient une maladie de Parkinson reliée à un tremblement essentiel familial. Nos résultats supportent l'hypothèse de Barbeau ${ }^{7.19}$ que le Parkinson est une maladie hétérogène dont certains sous-types (tel que la maladie de Parkinson à début précoce) ont une composante de susceptibilité génétique importante.

Can. J. Neurol. Sci. 1986; 13:248-251

Ever since Parkinson described Paralysis Agitans in 1817 , the question of the possible genetic origin of the disease has been raised. Different models of heredity have been proposed: an irregular dominant mode of mendelian transmission' an autosomal recessive mode in some pedigrees ${ }^{2}$ and a multifactorial model by most authors. ${ }^{3,4.5}$ Others, like Duvoisin (1984), ${ }^{6}$ conclude that no genetic component is involved and that the results are due to chance occurrence only.

That Parkinsonism may be a syndrome rather than a disease entity has been considered for many years and some authors divide the patients with Parkinsonism into three groups; postencephalitic, symptomatic and idiopathic Parkinsonism. Most genetic studies have involved the idiopathic group, which may not be homogeneous.

Martin $(1973)^{4}$ pointed out that when the available genetic data for Parkinson's disease fits an acceptable model, this does not provide proof that all cases of the disease are genetically determined or that the clinical syndrome of the idiopathic form reflects a specific homogeneous clinical or biochemical entity.

Recently Barbeau et al $(1982)^{7}$ emphasized that idiopathic Parkinson's disease is not homogeneous and that within the large idiopathic group there exists one or more sub-groups, such as early onset Parkinsonism patients who have an important genetic load, while others are without major genetic components.

This report describes the results of a familial aggregation study in a group of Mexican patients with Parkinson's disease and the sub-groups that we found in agreement with Barbeau's classification (1982).

\section{METHODS}

The index cases were 122 patients with Parkinson's disease obtained from the outpatient clinic of the National Institute of Neurology and Neurosurgery (I.N.N.N.) of Mexico City. All patients were examined by a neurologist. The diagnosis of Parkinson's disease was based on the presence of a constellation of signs which included at least two or more of the following: tremor, rigidity, bradykinesia and impaired postural stability. None were selected because of known family history of Parkinson's disease. The control groups consisted of the spouses of the index cases and some individuals that work in the Institution.

After the standard consultation, all patients and controls were interviewed by one of us to perform a careful pedigree

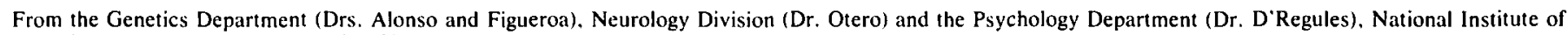
Neurology and Neurosurgery. Mexico City

Received July 23. 1985. Accepted in final form April 15, 1986.

Reprint requests to: Dr. Ma. Elisa Alonso-V. Head. Genetic Department Instituto Nacional de Neurologia Y Neurocirugia, Insurgentes Sur 3877 . Col. La Fama - Deleg. Tlalpan 14410 Mexico, D.F. 
focussed only on first degree relatives since it was not possible to obtain accurate information of more distant relatives. Criteria for the diagnosis of Parkinson's disease in a family member who was not available for examination included at least one of the following; diagnosis by a physician, an adequate description by a relative which included at least tremor and abnormal gait or rigidity. If there was doubt about the diagnosis the individual was assumed to be unaffected.

\section{RESULTS}

The sample consisted of 122 Mexican adult patients, 52 female and 70 male probands. The control group contained 50 men and 50 women matched for age and sex.

The mean ages of the female and male probands at the onset of the disease were 51.8 and 51.4 years respectively; if the early onset group were excluded, the mean age onset was 55.6 years and the mean age at onset in the early onset group was $29.7 \%$ years.

For the familial aggregation calculation we excluded 15 patients with symptomatic Parkinsonism (12.3\%) and 2 others with post encephalitic Parkinsonism (1.7\%); interestingly, none of these 17 patients had familial aggregation. The rest of the 105 patients (86\%) were considered idiopathic. In agreement with the classification proposed by Barbeau in $1982,{ }^{7}$ our 122 patients were sub-grouped as seen in Table 1.

In the idiopathic group we found positive familial aggregation in first degree relatives in $9.5 \%$ of the probands and $1 \%$ in the controls. Of the 105 index cases, $17(16.1 \%)$ had juvenile parkinsonism (term used by Yokochi and Narabayashi) ${ }^{9}$ or early onset Parkinsonism (onset before their 40th birthday). In this sub-group, four patients with typical features of Parkinson

Table 1: Classification of 122 patients with Parkinson's Disease based on the Classification by Barbeau et al (1982)

\begin{tabular}{llc}
\hline \hline & Type & No. of Patients \\
\hline Type I & Post-Enchephalitic & 2 \\
Type II & Idiopathic & 57 \\
& $\begin{array}{l}\text { IIa Tremor onset Form } \\
\text { IIb Akineto-Rigid Onset Form }\end{array}$ & 20 \\
Type III & Genetic & \\
& IIla Familial Metabolic & 0 \\
& $\quad$ Akineto-Rigid Syndrome & 6 \\
& IIla' Familial Tremor Onset Form & 5 \\
& IIIb Familial Essential Tremor & related Parkinsonism \\
& IIlc Familial Juvenile Parkinsonism & 17 \\
Type IV & Sympotomatic & 15 \\
\hline
\end{tabular}

disease (23.5\%) had familial history of Parkinson in first degree relatives (Figure 1, Table 2), and two more patients in this group had one second degree relative with Parkinson disease undergoing treatment in our Institute.

We found 6 index cases, with onset after 40 years, with Parkinson that began with tremor and persisted with it as the most important feature of the diseases who showed a positive family history of Parkinson in first degree relatives. (Table 3 ). In cases 1,2, 4, 6, 7 and 10, the first degree relative affected was examined by one of us and all had typical features of Parkinson disease, in cases 1 and 2 , the two affected sisters also had onset of the disease before age 40 .

In four cases, (3, 5, 8 and 9), in which the affected relatives were dead and there were no CAT scans, nor autopsy confirmation, the diagnosis was based solely on the description by the relatives. All of these affected relatives had onset of this disease after 40 years.

While 5 other patients $(4.7 \%)$ had family history of essential tremor with apparent dominant inheritance of the essential tremor within their families, in four cases at least one first degree relative in each family was examined by one of us and the diagnosis of essential tremor confirmed (Figure 2). In the control group, there were no cases of essential tremor. Consanguinity was $3.8 \%$ in our experimental sample and $2.9 \%$ in the control group.

In the symptomatic group, the final diagnosis can be seen in Table 4.

\section{Discussion}

The onset age in males and females proband is similar to that reported by other authors. ${ }^{8.10}$ Eighty six percent of the index

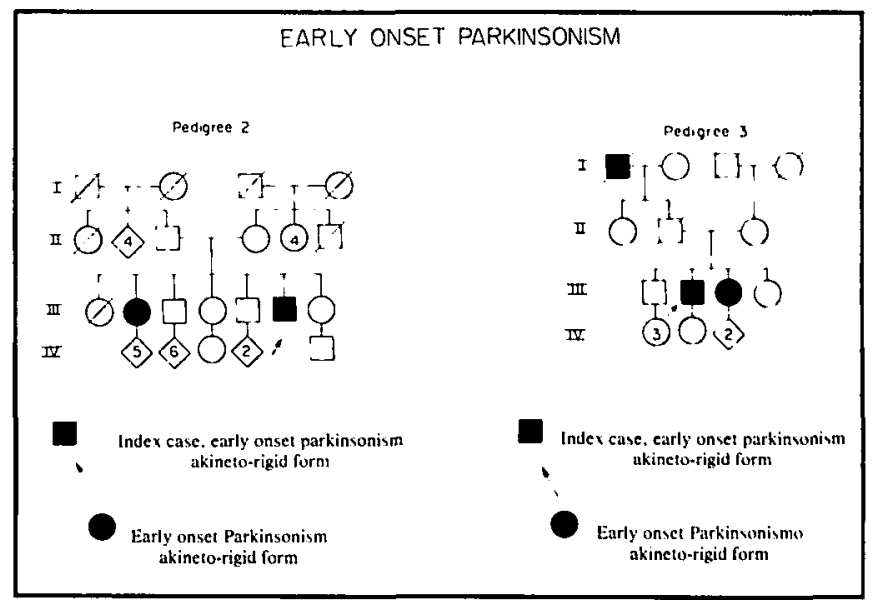

Figure I - Pedigree of two kinship with familial early onset Parkinsonism.

Table 2: Familial Early Onset Parkinsonism

\begin{tabular}{clcccrc}
\hline Case & Type & Age of onset & Duration & $\begin{array}{c}\text { First degree } \\
\text { affected relative }\end{array}$ & $\begin{array}{c}\text { Relative age } \\
\text { of onset }\end{array}$ \\
\hline 1 & Akineto-rigid form & 14 & 16 & Sister & 26 & Akineto-rigid Form \\
2 & Akineto-rigid form & 24 & 4 & Sister & 31 & Akineto-rigid Form \\
3 & Akineto-rigid form & 39 & 2 & Mother & 60 & $?$ \\
4 & Akineto-rigid form & 38 & 8 & Father & 65 & Akineto-rigid Form \\
\hline
\end{tabular}




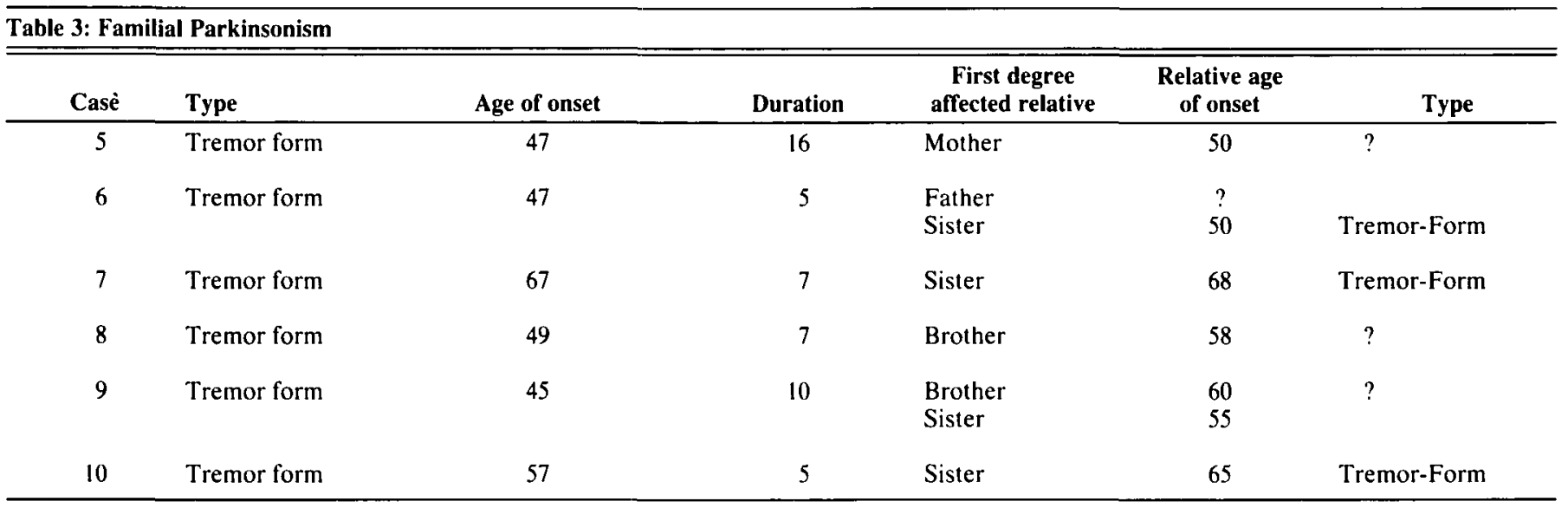

Table 4: Diagnosis in 15 patients with symptomatic Parkinson

\begin{tabular}{lc}
\hline \hline Diagnosis & No. Patients \\
\hline Parkinson induced by drugs & 1 \\
Shy-Drager Syndrome & 1 \\
Parkinson-Dementia Syndrome & 1 \\
Basal glanglia calcification & 1 \\
Arteritis & 1 \\
Cysticercosis & 4 \\
Lues & 3 \\
Multiple cerebral infarctions & 3 \\
\hline
\end{tabular}

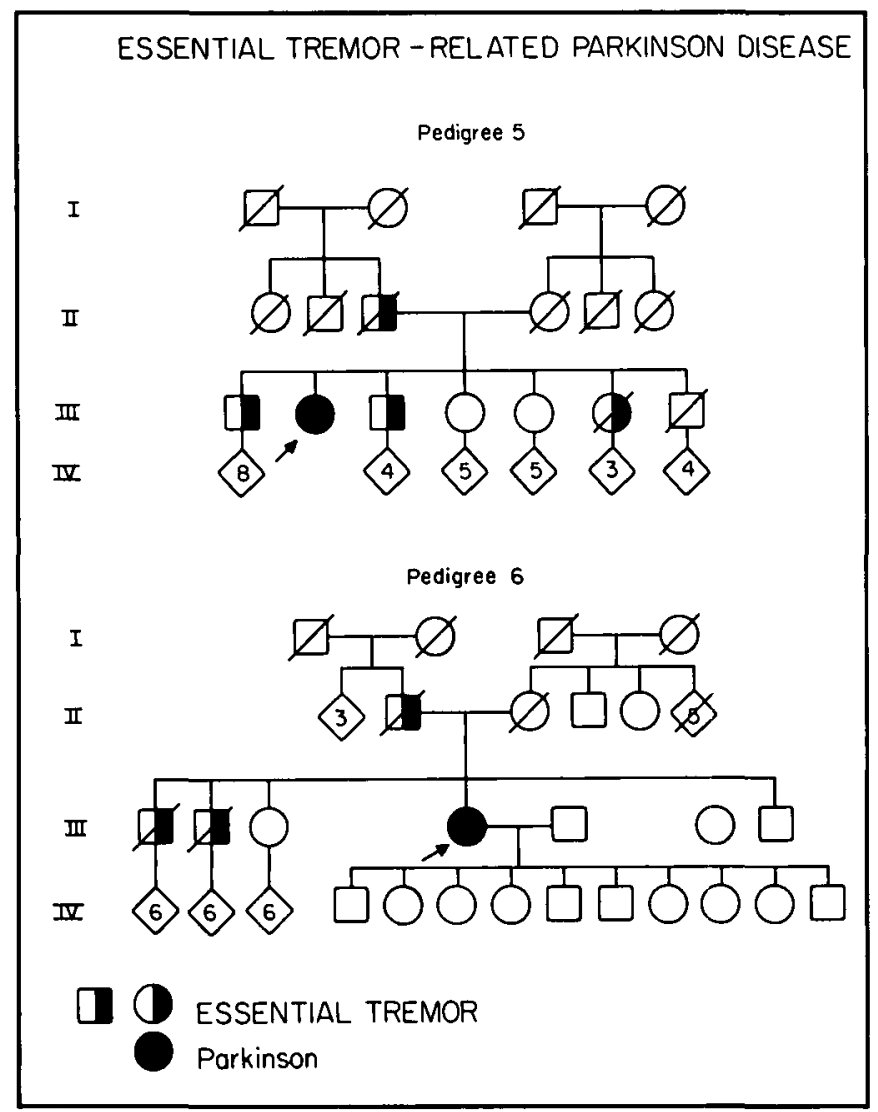

Figure $2-$ Pedigree of two families with Parkinson's disease in association with hereditary essential tremor over 2 generations. cases were of the idiopathic variety, similar to that reported in other series," i.e. $85.7 \%$.

The familial incidence in first degree relatives of Parkinson patients was $9.5 \%$ in this group of 105 patients with idiopathic Parkinson; this is similar to the reports of other authors, Barbeau (1982) ${ }^{7}$ for example, in 300 patients with Parkinson, reported a $13 \%$ positive family history in first degree relatives.

We found early onset Parkinsonism in $16.1 \%$ of our sample, Yokochi and Narabayashi $(1981)^{9}$ reported a frequency of such cases in Japan between 10 and $18 \%$ of all Parkinsonians and Barbeau et al $(1982)^{7} 9.4 \%$, these figures are similar to our own findings.

In this series, the early onset sub-group had an important genetic-predisposition; in these patients the incidence of positive family history was $23.5 \%$ which we consider is a significantly elevated incidence, although it is not as high as that found by the Japanese authors ${ }^{9}(42.5 \%)$ and by Barbeau et al $(46 \%){ }^{7}$

We also observed a sub-group of patients with onset of the disease with $\mathbf{4 0}$ years of age and predominance of tremor (subgroup IIla' Table 1), with an important familial incidence. Zetusky et al (1985), ${ }^{10}$ found that the tremor sub-group was often associated with a family history of Parkinsonism, confirming the findings of Roy et al (1983). ${ }^{12}$ Five of our families were found to have cases of both Parkinson and essential tremor. We do not have studies about the prevalence of essential tremor in the Mexican population, but in our control group there were no cases of essential tremor.

A slightly higher consanguinity rate is observed in the Parkinson group than in the controls, as reported by Roy et al 1983. ${ }^{12}$ We found consanguinity in three early onset non-familial patients, one familial early onset and one with the non-familial tremor form.

The problem of the heritability of Parkinson's disease has been discussed for many years and it is still subject to controversy. Some authors like Barbeau $(1982,1984)^{7.18 .19}$ are in favour of component of genetic susceptibility and others like Duvoisin et al $(1981,1984),{ }^{6,13}$ negate any genetic component to the disease. The existence of some hereditary disease like autosomal dominant olivopontocerebellar atrophy type $\mathrm{V}$, hereditary mental depression and taurine deficiency in which Parkinsonism is part of the clinical picture of the disease, is an indirect evidence of the presence of different genes that, in some way mimics Parkinsonism. ${ }^{14}$ 
Our results support the hypothesis that Parkinson is a heterogeneous disease and that the genetic component is different depending on the sub-group. Nevertheless our sample is too small to carry out proper genetic analysis. In the symptomatic group of patients, it is of interest to point out that in Parkinsonism induced by drugs, Myriantropoulos et al $(1969)^{15}$ found a 2.5\% frequency of affected relatives in 486 Parkinson disease index cases versus only $0.6 \%$ in 483 relatives of control subjects. In this study, we had only one patient with Parkinson induced by drugs and she did not have family antecedents of Parkinson.

In the symptomatic group (Table 4), we included some etiologic entities with a frequency not reported up to this time in other series. This probably depends on a regional frequency of specific pathologies. The most frequent etiology in this group was cysticercosis which corresponded to $3.2 \%$ of the symptomatic cases.

This variety must be included in the differential diagnosis of symptomatic Parkinson Syndrome in our country where cysticercosis is an important cause of nervous system affection. ${ }^{16}$

The heterogeneity of Parkinson disease and its multiple causes is manifested again in the report of Langston and Ballard (1983), ${ }^{17}$ where they describe the production of irreversible Parkinson in humans after the MPTP injection. As Barbeau $(1984)^{18}$ pointed out, it is possible that many people are constantly being exposed to products with a similar chemical conformation found in nature or industry.

\section{REFERENCES}

I. Mjönes H. Paralysis agitans. Acta psychiat neurol (1949) Supp 54

2. Dastur DK. A family with three cases of Parkinson's syndrome. Indian J Med Sci 1956; 10: 282-285.

3. Kondo K, Kurland L and Schull W. Parkinson's Disease: Genetic analysis and evidence of Multifactorial Etiology. Mayo Clinic Proceedings 1973; 48: 465-475.
4. Martin W, Young W and Enderson E. Parkinson's Disease: A Genetic Study. Brain 1973; 96: 495-506.

5. Young WI, Martin WE and Anderson VE. The distribution of ancestral secondary cases in Parkinson's disease. Clinical genetic 1977; 11: 189-192.

6. Duvoisin R. Is Parkinson's Disease Acquired or Inherited? Can J Neurol Sci 1984: 11: 151-155.

7. Barbeau A and Pourcher E. New Data on the Genetics of Parkinson's Disease. Can J Neurol Sci 1982; 9: 53-60.

8. Selby G. Parkinson's disease. In: P.J. Vinken and G.W. Bruyn Handbook of Clinical Neurology. Disease of the Basal Ganglia. Amsterdam North-Holland Publishing Company 1968: 173-211.

9. Yokochi $\mathrm{M}$ and Narabayashi $\mathrm{H}$. Clinical characteristic in juvenile Parkinsonism In: Research Progress in Parkinson's Disease (F. Clifford Rose and R. Capildeo Eds) Pitman Medical Turnbridge Wells, 1981, 35-39.

10. Zetusky WJ, Jankovic $\mathrm{J}$ and Pirozzolo FJ. The heterogeneity of Parkinson's disease; Clinical and prognostic implications. Neurology $1985 ; 35$ : 522-526.

11. Rajput AH, Offord KP, Beard MC and Kurlan LT. Epidemiology of Parkinsonism; Incidence, Classification and Mortality. Ann Neurol 1984; 16: 278-282.

12. Roy $M$, Boyer $L$ and Barbeau A. A prospective study of 50 cases of Familial Parkinson's Disease. Can J Neurol Sci 1983; 10: 37-42.

13. Duvoisin RC, Eldridge R, Williams A. Nutt J and Calne D. Twin study of Parkinson disease. Neurology 1981: 31: 77-80.

14. Perry TL, Bratty PJ, Hansen S, Kennedy J, Urquhart $N$ and Dolman CL. Hereditary Mental Depression and Parkinsonism with Taurine Deficiency. Arch Neurol 1975: 32: 108-113.

15. Myrianthopoulos NC, Waldrop FN and Vincent BL. A repeat study of hereditary predisposition in drug induced parkinsonism. In: Progress in Neuro-Genetics edited by A. Barbeau and J.R. Brunette, Excerpta med Int Cong Ser No 175 (1969): 486-491.

16. Otero E, Rodriguez $R$, Gutierrez $H$, Alonso ME. Figueroa $H$. Campos FJ. Ramírez I. El diagnóstico clínico en el Instituto de Neurología. Rev Inst Nal Neurol 1978: 3: 102-124.

17. Langston JW and Ballard PA. Parkinson's Disease in a chemist working with 1-Methyl-4-Phenyl-1.2,5.6, Tetrahydropyridine. New Engl J Med 1983; 309-310.

18. Barbeau A. Etiology of Parkinson`s Disease: A research - Strategy. Can J Neurol Sci 1984: 11: 24-28.

19. Barbeau A, Roy M. Familial Subsets in Idiopathic Parkinson's Disease. Can J Neurol Sci 1984; 11: 144-150. 